Jpn J Human Genet 41, 189-192, 1996

\title{
CONGENITAL BILATERAL PERISYLVIAN SYNDROME: FIRST REPORT IN A JAPANESE PATIENT
}

\author{
Haruo Hattori, ${ }^{1, *}$ Yoshihisa Higuchi, ${ }^{1}$ Toshiro MaIhara, ${ }^{1}$ \\ Eun-Young JunG, ${ }^{1}$ Kenshi Furusho, ${ }^{1}$ and Reinin Asato ${ }^{2}$ \\ ${ }^{1}$ Department of Pediatrics and ${ }^{2}$ Department of Nuclear Medicine, \\ Faculty of Medicine, Kyoto University, 54 Kawahara-cho, \\ Shogoin, Sakyo-ku, Kyoto 606, Japan
}

\begin{abstract}
Summary A Japanese boy with congenital bilateral perisylvian syndrome is described. He had oropharyngoglossal dysfunction and severe dysarthria. Magnetic resonance imaging of the brain disclosed bilateral perisylvian malformations suggesting polymicrogyria. The patient also showed mental retardation, epilepsy, and poor motor skills.

Key Words congenital bilateral perisylvian syndrome, neuronal migration disorder, polymicrogyria, pseudobulbar palsy, Foix-ChavanyMarie syndrome
\end{abstract}

\section{INTRODUCTION}

Congenital bilateral perisylvian syndrome is a congenital neurological syndrome characterized by pseudobulbar palsy and bilateral perisylvian polymicrogyria (Kuzniecky et al., 1993). Clinical manifestations of pseudobulbar palsy, congenital facio-pharyngo-glosso-masticatory diplegia represent developmental Foix-Chavany-Marie syndrome or bilateral anterior opercular syndrome, resulting from bilateral opercular lesions. This is the first report of a Japanese patient with this syndrome.

\section{CASE REPORT}

The patient was a 9-year-old Japanese boy with pseudobular palsy. His father, age 39 , his mother, age 34 , and the younger brother, age 4 , were all healthy. The parents were not consanguineous. The mother had a previous spontaneous abortion at 10 weeks of gestation, and the gestation of the patient was complicated by threatened abortion with vaginal bleeding at 5 months gestation. He was born by elective Cesarean section because of bicornate uterus. The gestational period was

Received October 3, 1995; Revised version accepted December 11, 1995.

* To whom correspondence should be addressed. 
35 weeks, and the birth weight was $2,642 \mathrm{~g}$. Delivery and the neonatal period were uneventful.

Delayed milestones were noticed during infancy. He held his head at 3 months, but sat alone at 13 months, and walked alone at 23 months. Development of expressive language was markedly delayed. At the age of 9 years, he could vocalize only a few words which were hardly comprehensible because of dysarthria. In contrast to expressive language, his perception of language showed better development. He understood spoken commands and conveyed his intention by body language. He is currently learning sign language. His intelligence quotient was 57 on a modified Gesell scale.

His physique was normal without any dysmorphic features. G-banded chromosomes of leukocytes were $46, X Y$. He had slightly weak vision since he developed bilateral rhegmatogenous retinal detachments necessitating surgery at the age of 8 years. His face was expressionless with weakness of the facial musculature. The orbicularis muscle were weak, and the mouth was always half-opened. He demonstrated slight dysphagia and constantly drooled, but the gag reflex could be elicited. The most striking feature of pseudobulbar palsy was limitation of tongue movement. He could neither protrude nor laterally move his tongue. He also had poor motor skills. He was unable to hop on one leg, and used his hands clumsily.

He had febrile convulsions at the age of 1 and 2 years. He developed a few episodes of brief nocturnal generalized tonic-clonic seizures at the age of 8 years. An awake record of the electroencephalograms (EEGs) revealed occasional spikes in the left central area. The background activity was in the normal range, alpha waves around $9 \mathrm{c} / \mathrm{sec}$. Epilepsy was controlled by carbamazepine.

Magnetic resonance imaging (MRI) taken at the age of 3 years showed bilateral perisylvian malformations suggesting polymicrogyria or macrogyria (Fig. 1). There were gyral abnormalities involving the bilateral perisylvian and perirolandic regions, extending high into the parietal regions. The cortex appeared thick and smooth, with the underlying white matter diminished.

\section{DISCUSSION}

Congenital bilateral perisylvian syndrome was named in a report of 31 similar cases in 1993 (Kuzniecky et al., 1993). Clinical, electroencephalographical, and neuroradiological characteristics have been delineated (Guerrini et al, 1992a, b; Kuzniecky et al., 1994a, b, c). Our patient represents a typical case of this syndrome. This patient met all the essential criteria established by Kuzniecky et al. (1993); oropharyngoglossal dysfuction, moderate to severe dysarthria, and bilateral perisylvian malformations on imaging. He also has all of the additional criteria; delayed milestones, epilepsy, mental retardation, and abnormal EEG, although he does not have other criteria of the syndrome; arthrogryposis multiplex, other limb malformations, or infantile spasms. Patients with this syndrome have been so far 

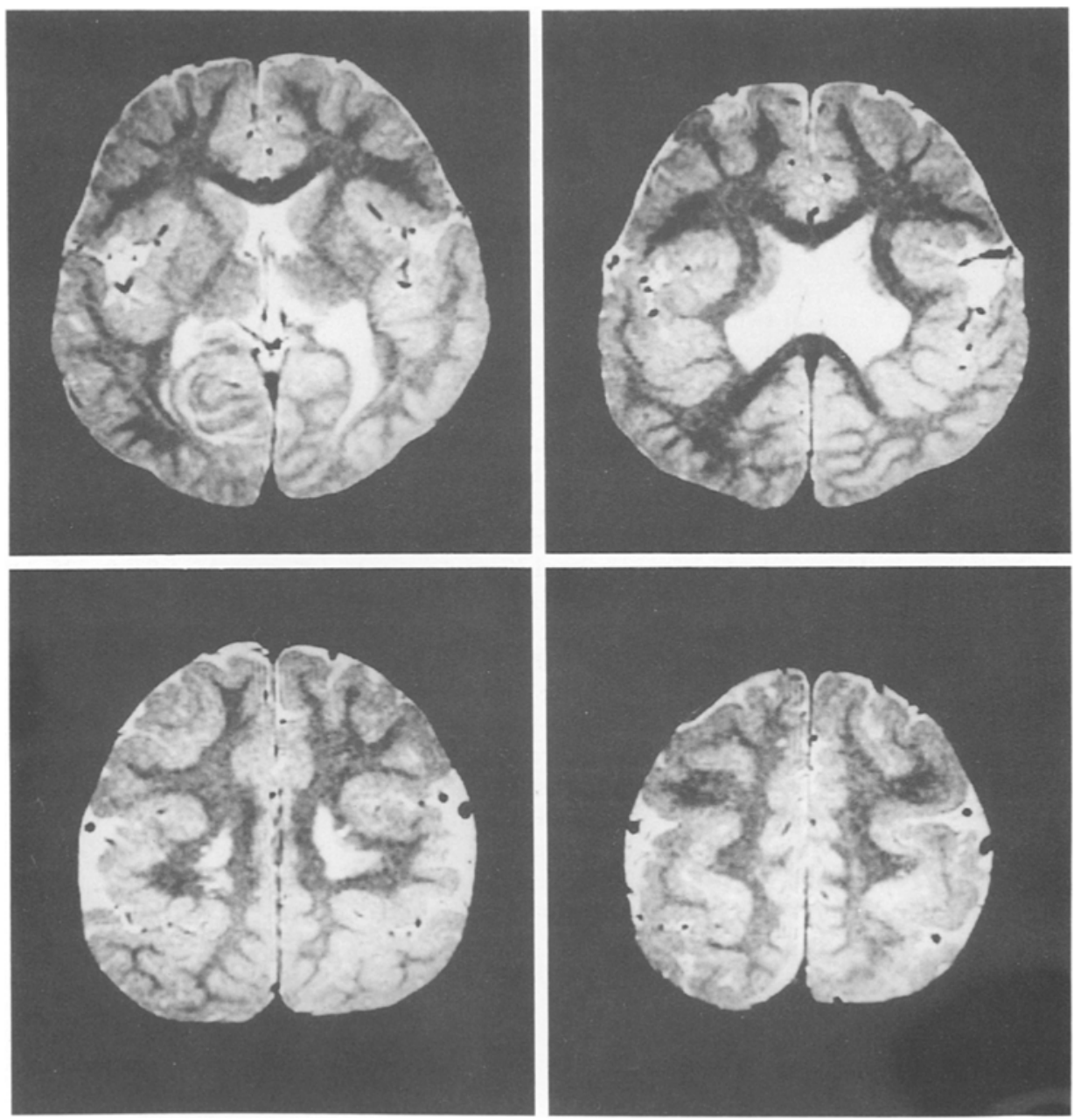

Fig. 1. T2-weighted images ( $T R=3,000 \mathrm{~ms}, T E=80 \mathrm{~ms}$ ) of cranial MRI.

reported in North America, Western Europe, and Korea (Kim et al., 1994). To our knowledge, this syndrome has not previously been reported among Japanese.

The neurological manifestations of this syndrome reflect the neuronal migration disorder of the bilateral perisylvian and perirolandic regions including the operculum. Although MRI cannot precisely differentiate between polymicrogyria and macrogyria (Kuzniecky et al., 1989), autopsy findings of patients with this syndrome demonstrated that the underlying abnormality is polymicrogyria (Becker et al., 1989; Shevell, 1992; Kuzniecky, 1994a).

The etiology of this syndrome remains unknown, although restricted ischemic injury during fetal brain development is postulated for the development of perisylvian polymicrogyria (Kuzniecky et al., 1993). A genetic factor should be 
contributory, since this syndrome was reported in identical twins (Graff-Radford et al., 1986) and in siblings (Kuzniecky, 1993).

\section{REFERENCES}

Becker PS, Dixon AM, Troncoso JC (1989): Bilateral opercular polymicrogyria. Ann Neurol 25: 90-92

Graff-Radford NR, Bosch EP, Stears JC, Tranel D (1986): Developmental Foix-Chavany-Marie syndrome in identical twins. Ann Neurol 20: 632-635

Guerrini R, Dravet C, Raybaud C, Roger J, Bureau M, Battaglia A, Livet M-O, Colicchio G, Robain O (1992a): Neurological findings and seizure outcome in children with bilateral opercular macrogyric-like changes detected by MRI. Dev Med Child Neurol 34: 694-705

Guerrini R, Dravet C, Raybaud C, Roger J, Bureau M, Battaglia A, Livet M-O, Colicchio G, Robain O (1992b): Epilepsy and focal gyral anomalies detected by MRI: electroclinicomorphological correlations and follow-up. Dev Med Child Neurol 34: 706-718

Kim HI, Palmini A, Choi HY, Kim YH, Lee JC (1994): Congenital bilateral perisylvian syndrome: analysis of the first four reported Korean patients. J Korean Med Sci 9: 335-340

Kuzniecky R, Andermann F, Tampieri D, Melanson D, Olivier A, Leppik I (1989): Bilateral central macrogyria: epilepsy, pseudobulbar palsy, and mental retardation-a recognizable neuronal migration disorder. Ann Neurol 25: 547-554

Kuzniecky R, Andermann F, Guerrini R, The CBPS multicenter collaborative study (1993): Congenital bilateral perisylvian syndrome: study of 31 patients. Lancet 341: 608-612

Kuzniecky R, Andermann F, The CBPS study group (1994a): The congenital bilateral perisylvian syndrome: imaging findings in a multicenter study. Am J Neuroradiol 15: 139-144

Kuzniecky R, Andermann F, Guerrini R, The CBPS multicenter collaborative study (1994b): The epileptic spectrum in the congenital bilateral perisylvian syndrome. Neurology 44: 379-385

Kuzniecky R, Andermann F, Guerrini R (1994c): Infantile spasms: an early epileptic manifestation in some patients with the congenital bilateral perisylvian syndrome. J Child Neurol 9: $420-423$

Shevell MI, Carmant L, Meagher-Villemure K (1992): Developmental bilateral perisylvian dysplasia. Pediatr Neurol 8: 299-302 